\title{
Treatment of benign prostatic hyperplasia
}

\section{TRATAMENTO DA HIPERPLASIA PROSTÁtICA BENIGNA}

Authorship: Brazilian Society of Urology (SBU)

Participants: Ricardo Vita Nunes ${ }^{1}$, João Manzano ${ }^{1}$, José Carlos Truzzi ${ }^{1}$, Aguinaldo Nardi ${ }^{1}$, Antonio Silvinato ${ }^{1}$, Wanderley Marques Bernardo ${ }^{2}$

Final draft: August 7, 2016

${ }^{1}$ Sociedade Brasileira de Urologia (SBU)

${ }^{2}$ Associação Médica Brasileira (AMB)

The Guidelines Project, an initiative of the Brazilian Medical Association, aims to combine information from the medical field in order to standardize procedures to assist the reasoning and decision-making of doctors.

The information provided through this project must be assessed and criticized by the physician responsible for the conduct that will be adopted, depending on the conditions and the clinical status of each patient.

\section{Grades of Recommendation AND LeVELS OF EVIDENCE}

A: Experimental or observational studies of higher consistency.

B: Experimental or observational studies of lower consistency.

C: Cases reports (non-controlled studies).

D: Opinion without critical evaluation, based on consensus, physiological studies or animal models.

\section{Objective}

To advise physicians on the most indicated therapeutic possibilities that can improve the symptoms of the urinary tract and the quality of life of the patient, as well as prevent complications related to the evolution of benign prostatic hyperplasia.

\section{INTRODUCTION}

A significant proportion of men with benign prostatic hyperplasia (BPH) do not require treatment. Such observation does not necessarily imply the absence of treatment. We can achieve improvement of lower urinary tract symptoms (LUTS) by adopting some non-pharmacological measures, such as reducing nocturnal water intake, reducing caffeine and alcohol consumption, and avoiding the use of decongestants and antihistamines. Men with mild or moderate urinary tract symptoms that have minimal impact on quality of life are candidates for active monitoring requiring annual reevaluation. ${ }^{1}(\mathbf{D})$

\section{What ARE THE THERAPEUTIC POSSIBILITIES FOR MEDICINES THAT IMPROVE URINARY SYMPTOMS AND PREVENT COMPLICATIONS RELATED TO THE PROGRESSION OF BENIGN PROSTATIC HYPERPLASIA?}

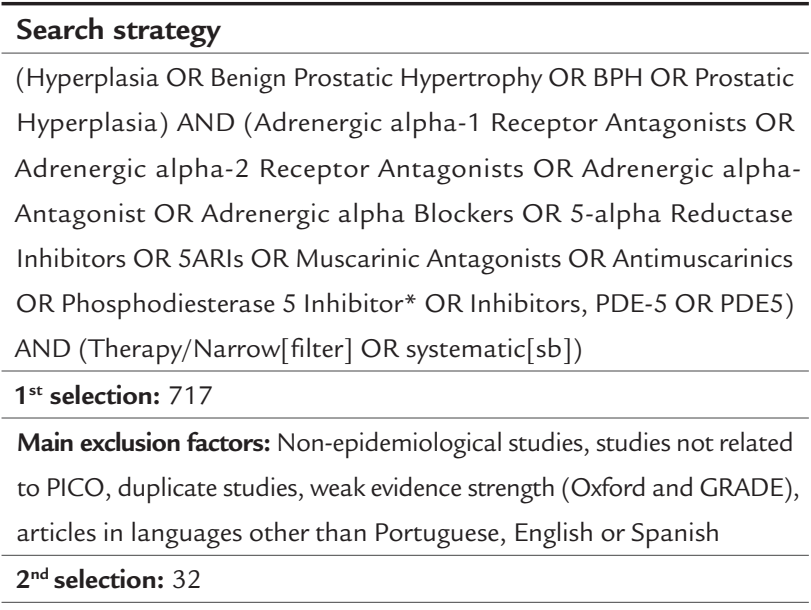

Phytotherapy

Due to the lack of scientific evidence, the systematic use of herbal medicines, such as Saw palmetto (Serenoa repens) extract, to treat BPH-associated LUTS (BPH-LUTS) is not recommended. ${ }^{2}(\mathbf{A})$ The PROCOMB trial showed that the combination therapy of tamsulosin and phytotherapy based on Serenoa repens plus selenium and lycopene was more effective in improving International Prostate Symptom Score (I-PSS) than either therapy alone 
(18.2\% using combined therapy vs. tamsulosin alone $[\mathrm{p}<0.05]$ and vs. phytotherapy alone $[\mathrm{p}<0.05]) .{ }^{3}(\mathbf{A})$

\section{Alpha-blockers}

These are involved in the regulation of smooth muscle tone of prostate and bladder neck, and are critical mediators of lower urinary tract symptoms and the pathophysiology of BPH-LUTS. For this reason, alpha-blockers are first-line drugs in the treatment of BPH symptoms. ${ }^{3}$ (A) Alpha-blockers currently available: doxazosin, tamsulosin, alfuzosin, terazosin and silodosin, the last one not available in Brazil. Although there are small differences between alpha-blockers, they are all equally effective and lead to a 4- to 6-point objective drop in I-PSS, enough for most patients to report significant improvement in symptoms. These are considered to be very efficient drugs as monotherapy in the treatment of BPH-LUTS. ${ }^{4,5}$ (A) Patients candidate for monotherapy with alpha-blockers are mainly those with moderate to severe LUTS and with an impact on quality of life. Symptomatic improvement is perceived by the patient within four weeks and may extend over a long period. ${ }^{3}$ (A) Alpha-blockers are effective in the treatment of BPH-LUTS, but their mechanism of action does not prevent disease progression, only relief of symptoms. ${ }^{4,5}$ (A) The most common side effects of alpha-blockers are asthenia, dizziness and orthostatic hypotension. ${ }^{5}$ (A) Ejaculatory dysfunction (retrograde ejaculation, reduction of seminal ejaculated volume) is frequently reported by patients. ${ }^{6}(\mathbf{A})$

\section{5-alpha-reductase inhibitors (i5ARs)}

There are currently two drugs that act by inhibiting 5AR: finasteride and dutasteride. Finasteride is a selective inhibitor of type II isoenzyme, whereas dutasteride is a non-selective inhibitor, affecting type I and II isoenzymes. i5ARs may be prescribed to men with lower urinary tract symptoms and enlarged prostate $(>40$ $\mathrm{mL}$ ) or high prostate-specific antigen (PSA) levels (> 1.6 $\mathrm{ng} / \mathrm{mL}$ ) and may prevent disease progression, reducing both the need for surgery and acute urinary retention. ${ }^{4,7-10}$ $(\mathbf{A})^{11}(\mathbf{B})$ One limitation to the use of monotherapy with i5ARs is the onset of action: improvement of BPH-LUTS takes between 4 and 6 months of therapy. Finasteride and dutasteride have similar efficacy in reducing prostate volume and improving urinary symptoms in $\mathrm{BPH} .{ }^{12}$ (B) The most relevant adverse effects include decreased libido, erectile dysfunction and ejaculation disorders. One to $2 \%$ of the patients develop gynecomastia (enlargement of the breasts with increased breast or nipple sensitivity). ${ }^{13}(\mathbf{A})$

\section{Antimuscarinic drugs}

These drugs have the property of inhibiting the action of acetylcholine and thus reducing the contractility of the detrusor muscle. Oxybutynin, tolterodine, darifenacin and solifenacin are currently available in Brazil. Muscarinic receptor antagonists should be considered in men with LUTS who have predominantly vesical storage symptoms. ${ }^{14}(\mathbf{A})$ This class of drugs should be used with caution in men with BPH and infravesical obstruction, especially with high post-voidal residual volume, due to the possibility of incomplete emptying and the development of acute urinary retention. ${ }^{14}(\mathbf{A})$ Common side effects include dry mouth, constipation, urinary difficulties, nasopharyngitis, dizziness, confusion and restlessness.

\section{Beta-3 agonists}

Beta-3 agonists, a new class of drugs for treatment of bladder storage symptoms, stimulates the sympathetic system during bladder filling, promoting relaxation of the detrusor muscle, increasing bladder functional capacity, decreasing urinary frequency and urinary urgency episodes, as well as urinary urge. Since it does not affect the parasympathetic system, there is no interference in detrusor contraction and, thus, in the voiding process, which minimizes the risk of urinary retention. Mirabegron, a beta-3 agonist, did not adversely affect voiding urodynamics (maximum urinary flow and detrusor pressure at maximum urinary flow) compared with placebo after 12 weeks of treatment in a double blind, placebo controlled study..$^{15}$ (A)

Combination therapy (antimuscarinic drugs and alpha-1 blocker) Combination of anticholinergic drugs and alpha-1 blocker may reduce storage symptoms and urinary frequency, according to a long term study. ${ }^{19}$ Although it can increase the risk of acute urinary retention in patients with $\mathrm{BPH}$ with baseline postvoid volume $>150 \mathrm{~mL}$, the rate of acute urinary retention is reduced in patients with postvoid volume $<150 \mathrm{~mL}$, around $1 \% .{ }^{16-19}(\mathbf{A})$

\section{Combination therapy (alpha-blocker and i5AR)}

The combination of alpha-blockers and i5ARs is an effective treatment for patients with moderate to severe LUTS, increased prostate volume (> $40 \mathrm{~mL}$ ), high PSA (> $1.6 \mathrm{ng} / \mathrm{mL})$, and reduced maximum urinary flow. Combination therapy is valid not only for relief of symptoms but also to reduce the risk of progression of $\mathrm{BPH}$, it means increase of the symptom score, surgical treatment due urinary retention, urinary incontinence, urinary tract infection and renal failure. ${ }^{4,7-10}(\mathbf{A})^{11}(\mathbf{B})$ It is not recommended for treatment lasting less than one year and should be prescribed with 
caution in men with suspected infravesical obstruction and high post-voidal residual urine volume..$^{711}(\mathbf{A})^{12}(\mathbf{B})$. A multicenter, randomized, non-blinded study, that included treatment-naive patients with moderately symptomatic $\mathrm{BPH}$, concluded that a fixed dose of dutasteride/tamsulosin may reduce the risk of clinical progression and improve symptoms compared to expectant treatment, with optional tamsulosin prescription (initiation of protocol-defined therapy if symptoms did not improve) ${ }^{20}(\mathbf{A})$

\section{Phosphodiesterase-5 inhibitors (iPDE5s)}

Several studies demonstrate the effect of iPDE5s on the treatment of $\mathrm{BPH}^{21-24}(\mathbf{A})$ The likely mechanisms of action stem from effects on smooth muscle relaxation, endothelial cell proliferation, improved blood flow, and activity on the prostatic efferent nerves. ${ }^{25}$ (D) Currently, tadalafil (5 $\mathrm{mg}$ once daily) is approved in Brazil for the treatment of urinary symptoms associated with $\mathrm{BPH}$. This indication is based on double-blind randomized placebo-controlled trials (RCT), that showed a significant reduction of I-PSS after twelve weeks. ${ }^{22,23,26,27}$ (A) A prospective placebo-controlled study of tadalafil with tamsulosin used as an active comparator showed that tadalafil led to a decrease in tamsulosin-like I-PSS as early as week $1 .{ }^{23}(\mathbf{A})$ Since iPDE5 is indicated for the treatment of erectile dysfunction, this class of medication may be an option in the treatment of patients presenting both disorders. ${ }^{22,23,26}(\mathbf{A})$

\section{Combination therapy (iPDE5s and alpha-blockers)}

The simultaneous use of iPDE5s and alpha-blockers may cause symptomatic hypotension. Such a risk can be reduced with tadalafil, uroselective alpha-blockers (tamsulosin, alfuzosin), low doses of alpha-blockers, separating doses for several hours instead of using them simultaneously, or waiting until the patient is taking a stable dose of a drug to initiate the second one. ${ }^{28}(\mathbf{D})$ A systematic review with meta-analysis included seven RCTs [ $\mathrm{N}=515$ patients] and evaluated the efficacy of iPDE5s alone or combined with alpha-blockers in the treatment of erectile dysfunction and LUTS, with a follow-up ranging from 60 days to three months. For the treatment of erectile dysfunction, combination therapy produced a statistically significant increase in the International Index of Erectile Function-Erectile Function (IIEF-EF) compared with the group that used iPDE5s alone (MD 2.25, 95CI 0.07-4.43; six trials; $\mathrm{I}^{2}=78 \%$ ). In the treatment of LUTS, the combination of iPDE5s and alpha-blockers produced statistically significant reductions in I-PSS score (MD -4,21, 95CI -7.09--1.32; five trials; $\mathrm{I}^{2}=93 \%$ ) and increase in maximum urinary flow $\left(\mathrm{Q}_{\max }\right)$ [MD 1.43, 95CI 0.38-2.47; four trials; $\left.{ }^{2}=0 \%\right]$. These results should be examined with caution on account of the high heterogeneity between studies for some outcomes, but we can infer that adding iPDE5s to alpha-blockers can improve BPH-LUTS. ${ }^{29}$ (A)

\section{Combination therapy (iPDE5s and i5ARs)}

In an RCT with confidence intervals including clinically unimportant differences, 696 men aged $\geq 45$ years old and with $\mathrm{BPH}$ were randomized to tadalafil $5 \mathrm{mg}$ once daily plus finasteride $5 \mathrm{mg}$ /day or placebo plus finasteride $5 \mathrm{mg} /$ day for 26 weeks. Prostate symptoms were assessed by I-PSS. At baseline, all patients had I-PSS $\geq 13$ points, prostate volume $\geq 30 \mathrm{cc}$ and had never been treated with 5-phosphodiesterase inhibitors. 592 patients (85\%) completed the study. Combination therapy (tadalafil + finasteride) compared to finasteride alone reduced the mean I-PSS after 26 weeks by 5.5 points vs. 4.5 points, respectively (minimum mean square error of 1 point, $95 \mathrm{CI} 0.2-1.9$ points). For this comparison, the treatment-related adverse event rate (mild/ moderate) was $31 \%$ vs. $27 \%$ (p-value was not reported). Combination therapy, compared to finasteride alone, showed patient improvement, but not an overall impression of clinical improvement. ${ }^{30}(\mathbf{A})$ Therefore, the addition of tadalafil to finasteride may moderately improve urinary symptoms in men with BPH. ${ }^{30}(\mathbf{A})$

The addition of tadalafil to finasteride cannot increase the response to treatment clinically significantly at week 26 , based on a post hoc secondary analysis of the RCT described above. ${ }^{30}$ (A) Clinically significant response to treatment was defined as a reduction $\geq 3$ points or $\geq 25 \%$ in the total I-PSS. Comparing the combination therapy (tadalafil + finasteride) with finasteride alone at week 26, the $\geq 3$-point reduction in I-PSS was $71.4 \%$ vs. $70.2 \%$, respectively (not significant) and the $\geq 25 \%$ reduction in I-PSS was $62 \%$ vs. $58.3 \%$ (not significant). Combination therapy was significantly associated with greater satisfaction with the treatment, in a pre-specified analysis. ${ }^{31}(\mathbf{B})$

In a subgroup analysis, also part of this study, including 404 sexually active men, tadalafil plus finasteride was associated with a higher score for erectile function compared to finasteride alone ( $\mathrm{p}<0.001$ for all moments analyzed). ${ }^{30}(\mathbf{A})$

\section{ReCOMmendation}

- Men with mild or moderate symptoms, with minimal impact on quality of life, can be followed up with active monitoring. (A)

- Alpha-blockers are recommended in the treatment of BPH-LUTS, with rapid symptom improvement, but its mechanism of action does not interfere with disease progression. (A) 
- i5ARs are recommended for men with LUTS, enlarged prostate, and/or high PSA levels. Results begin to be felt after a few months (4 to 6 months), but can prevent disease progression by reducing the need for surgery and acute urinary retention. (A)

- i5AR therapy combined with alpha-blockers is recommended for men with moderate to severe LUTS, enlarged prostate and/or high PSA levels, and reduced maximum urinary flow. (A)

- i5ARs therapy combined with alpha-blockers is not recommended for treatment lasting less than one year. (A)

- Muscarinic receptor antagonists and beta-3 agonists should be considered with caution in men with LUTS who have predominantly bladder storage symptoms. (A)

- Anticholinergic therapy, used alone or in combination with alpha-1 blocker, increases the risk of acute urinary retention in patients with BPH. (A)

- iPDE5s are recommended for the treatment of BPH-LUTS. This therapeutic class may be an option in the treatment of patients with erectile dysfunction and BPH-LUTS. (A)

- Addition of iPDE5s to alpha-blockers may improve BPH-LUTS. (A)

- Tadalafil plus finasteride is associated with an improvement in erectile function compared to finasteride alone. (A)

- Patients should be advised of the possible side effects of BPH drug therapy. (D)

- Due to the lack of scientific evidence, there is no recommendation for the use of herbal medicines in the treatment of BPH-LUTS. (A)

\section{References}

1. Wiygul J, Babayan RK. Watchful waiting in benign prostatic hyperplasia. Curr Opin Urol. 2009; 19(1):3-6

2. Tacklind J, Macdonald R, Rutks I, Stanke JU, Wilt TJ. Serenoa repens for benign prostatic hyperplasia. Cochrane Database Syst Rev. 2012 Dec 12; 12:CD001423.

3. Morgia G, Russo GI, Voce S, Palmieri F, Gentile M, Giannantoni A, et al. Serenoa repens, lycopene and selenium versus tamsulosin for the treatment of LUTS/BPH. An Italian multicenter double-blinded randomized study between single or combination therapy (PROCOMB trial). Prostate. 2014; 74(15):1471-80.

4. McConnell JD, Roehrborn CG, Bautista OM, Andriole GL Jr, Dixon CM, Kusek JW, et al.; Medical Therapy of Prostatic Symptoms (MTOPS) Research Group. The long-term effect of doxazosin, finasteride, and combination therapy on the clinical progression of benign prostatic hyperplasia. N Engl J Med. 2003; 349(25):2387-98.

5. Nickel JC, Sander S, Moon TD. A meta-analysis of the vascular-related safety profile and efficacy of alpha-adrenergic blockers for symptoms related to benign prostatic hyperplasia. Int J Clin Pract. 2008; 62(10):1547-59.

6. Novara G, Chapple CR, Montorsi F. Individual patient data from registrational trials of silodosin in the treatment of non-neurogenic male lower urinary tract symptoms (LUTS) associated with benign prostatic hyperplasia (BPH): subgroup analyses of efficacy and safety data. BJU Int. 2015; 115(5):802-14.

7. Roehrborn CG, Boyle P, Bergner D, Gray T, Gittelman M, Shown T, et al. Serum prostate-specific antigen and prostate volume predict long-term changes in symptoms and flow rate: results of a four-year, randomized trial comparing finasteride versus placebo. PLESS Study Group. Urology. 1999; 54(4):662-9.

8. Roehrborn CG, Siami P, Barkin J, Damião R, Major-Walker K, Morrill B, et al. The effects of dutasteride, tamsulosin and combination therapy on lower urinary tract symptoms in men with benign prostatic hyperplasia and prostatic enlargement: 2-year results from the CombAT study. J Urol. 2008; 179(2):616-21; discussion 621.

9. Roehrborn CG, Barkin J, Tubaro A, Emberton M, Wilson TH, Brotherton BJ, et al. Influence of baseline variables on changes in International Prostate Symptom Score after combined therapy with dutasteride plus tamsulosin or either monotherapy in patients with benign prostatic hyperplasia and lower urinary tract symptoms: 4-year results of the CombAT study. BJU Int. 2014; 113(4):623-35.

10. Clark RV, Hermann DJ, Cunningham GR, Wilson TH, Morrill BB, Hobbs $\mathrm{S}$. Marked suppression of dihydrotestosterone in men with benign prostatic hyperplasia by dutasteride, a dual 5 alpha-reductase inhibitor. J Clin Endocrinol Metab. 2004; 89(5):2179-84.

11. Boyle P, Roehrborn C, Harkaway R, Logie J, de la Rosette J, Emberton M. 5-Alpha reductase inhibition provides superior benefits to alpha blockade by preventing AUR and BPH-related surgery. Eur Urol. 2004; 45(5):620-6; discussion 626-7.

12. Nickel JC, Gilling P, Tammela TL, Morrill B, Wilson TH, Rittmaster RS Comparison of dutasteride and finasteride for treating benign prostatic hyperplasia: the Enlarged Prostate International Comparator Study (EPICS). BJU Int. 2011; 108(3):388-94.

13. Loke YK, Ho R, Smith M, Wong O, Sandhu M, Sage W, Singh S. Systematic review evaluating cardiovascular events of the 5-alpha reductase inhibitorDutasteride. J Clin Pharm Ther. 2013; 38(5):405-15.

14. Kaplan SA, Roehrborn CG, Abrams P, Chapple CR, Bavendam T, Guan Z. Antimuscarinics for treatment of storage lower urinary tract symptoms in men: a systematic review. Int J Clin Pract. 2011; 65(4):487-507.

15. Nitti VW, Rosenberg S, Mitcheson DH, He W, Fakhoury A, Martin NE. Urodynamics and safety of the $\beta_{3}$-adrenoceptor agonist mirabegron in males with lower urinary tract symptoms and bladder outlet obstruction. J Urol 2013; 190(4):1320-7.

16. Filson CP, Hollingsworth JM, Clemens JQ, Wei JT. The efficacy and safety of combined therapy with $\alpha$-blockers and anticholinergics for men with benign prostatic hyperplasia: a meta-analysis. J Urol. 2013; 190(6):2153-60

17. Hao N, Tian Y, Liu W, Wazir R, Wang J, Liu L, et al. Antimuscarinics and $\alpha$-blockers or $\alpha$-blockers monotherapy on lower urinary tract symptoms: a meta-analysis. Urology. 2014; 83(3):556-62.

18. van Kerrebroeck P, Chapple C, Drogendijk T, Klaver M, Sokol R, Speakman $\mathrm{M}$, et al. Combination therapy with solifenacin and tamsulosin oral controlled absorption system in a single tablet for lower urinary tract symptoms in men: efficacy and safety results from the randomised controlled NEPTUNE trial. Eur Urol. 2013; 64(6):1003-12.

19. Drake MJ, Chapple C, Sokol R, Oelke M, Traudtner K, Klaver M et al. Longterm safety and efficacy of single-tablet combinations of solifenacin and tamsulosin oral controlled absorption system in men with storage and voiding lower urinary tract symptoms: results from the NEPTUNE Study and NEPTUNE II open-label extension. Eur Urol. 2015; 67(2):262-70.

20. Roehrborn CG, Oyarzabal Perez I, Roos EP, Calomfirescu N, Brotherton B, Wang F, et al. Efficacy and safety of a fixed-dose combination of dutasteride and tamsulosin treatment (Duodart(®)) compared with watchful waiting with initiation of tamsulosin therapy if symptoms do not improve, both provided with lifestyle advice, in the management of treatment-naive men with moderately symptomatic benign prostatic hyperplasia: 2-year CONDUCT study results. BJU Int. 2015; 116(3):450-9.

21. Donatucci CF, Brock GB, Goldfischer ER, Pommerville PJ, Elion-Mboussa A, Kissel JD, et al. Tadalafil administered once daily for lower urinary tract symptoms secondary to benign prostatic hyperplasia: a 1-year, open-label extension study. BJU Int. 2011; 107(7):1110-6.

22. Egerdie RB, Auerbach S, Roehrborn CG, Costa P, Garza MS, Esler AL, et al. Tadalafil 2.5 or $5 \mathrm{mg}$ administered once daily for 12 weeks in men with both erectile dysfunction and signs and symptoms of benign prostatic hyperplasia: results of a randomized, placebo-controlled, double-blind study. J Sex Med. 2012; 9(1):271-81.

23. Oelke M, Giuliano F, Mirone V, Xu L, Cox D, Viktrup L. Monotherapy with tadalafil or tamsulosin similarly improved lower urinary tract symptoms suggestive of benign prostatic hyperplasia in an international, randomised, parallel, placebo-controlled clinical trial. Eur Urol. 2012; 61(5):917-25. 
24. Gacci M, Corona G, Salvi M, Vignozzi L, McVary KT, Kaplan SA, et al. A systematic review and meta-analysis on the use of phosphodiesterase 5 inhibitors alone or in combination with $\alpha$-blockers for lower urinary tract symptoms due to benign prostatic hyperplasia. Eur Urol. 2012 61(5):994-1003

25. Andersson KE, de Groat WC, McVary KT, Lue TF, Maggi M, Roehrborn CG, et al. Tadalafil for the treatment of lower urinary tract symptoms secondary to benign prostatic hyperplasia: pathophysiology and mechanism(s) of action. Neurourol Urodyn. 2011; 30(3):292-301.

26. Porst H, McVary KT, Montorsi F, Sutherland P, Elion-Mboussa A, Wolka $\mathrm{AM}$, et al. Effects of once-daily tadalafil on erectile function in men with erectile dysfunction and signs and symptoms of benign prostatic hyperplasia. Eur Urol. 2009; 56(4):727-35.

27. Porst H, Oelke M, Goldfischer ER, Cox D, Watts S, Dey D, et al. Efficacy and safety of tadalafil $5 \mathrm{mg}$ once daily for lower urinary tract symptoms suggestive of benign prostatic hyperplasia: subgroup analyses of pooled data from 4 multinational, randomized, placebo-controlled clinical studies. Urology. 2013; 82(3):667-73.
28. Schwartz BG, Kloner RA. Drug interactions with phosphodiesterase-5 inhibitors used for the treatment of erectile dysfunction or pulmonary hypertension. Circulation. 2010; 122(1):88-95.

29. Yan H, Zong H, Cui Y, Li N, Zhang Y. The efficacy of PDE5 inhibitors alone or in combination with alpha-blockers for the treatment of erectile dysfunction and lower urinary tract symptoms due to benign prostatic hyperplasia: a systematic review and meta-analysis. J Sex Med. 2014; 11(6):1539-45.

30. Casabé A, Roehrborn CG, Da Pozzo LF, Zepeda S, Henderson RJ, Sorsaburu $S$, et al. Efficacy and safety of the coadministration of tadalafil once daily with finasteride for 6 months in men with lower urinary tract symptoms and prostatic enlargement secondary to benign prostatic hyperplasia. J Urol 2014; 191(3):727-33.

31. Roehrborn CG, Casabé A, Glina S, Sorsaburu S, Henneges C, Viktrup L. Treatment satisfaction and clinically meaningful symptom improvement in men with lower urinary tract symptoms and prostatic enlargement secondary to benign prostatic hyperplasia: secondary results from a 6-month, randomized, double-blind study comparing finasteride plus tadalafil with finasteride plus placebo. Int J Urol. 2015; 22(6):582-7. 